\title{
ERRATUM
}

\section{Erratum to: Misuse of Respiratory Inhalers in Hospitalized Patients with Asthma or COPD}

Valerie G. Press, MD, MPH', Vineet M. Arora, MD, MAPP², Lisa M. Shah, MD, $M A^{3}$, Stephanie L. Lewis, BA ${ }^{4}$, Krystal IVy, BA ${ }^{4}$, Jeffery Charbeneau, MS ${ }^{4}$, Sameer Badlani, MD ${ }^{1,5}$, Edward Nareckas, MD ${ }^{4}$, Antoinette Mazurek, $\mathrm{MS}^{4}$, and Jerry A. Krishnan, MD, PhD ${ }^{4,6}$

'Department of Medicine, University of Chicago, Section of Hospital Medicine, Chicago, IL, USA; ${ }^{2}$ Department of Medicine, University of Chicago, Section of General Internal Medicine, Chicago, IL, USA; ${ }^{3}$ Avalere Health, LLC, Washington, DC, USA; ${ }^{4}$ Department of Medicine, University of Chicago, Asthma and COPD Center, Section of Pulmonary and Critical Care, Chicago, IL, USA; ${ }^{5}$ Mercy Hospital and Medical Center, Chicago, IL, USA; ${ }^{6}$ Department of Health Studies, University of Chicago, Chicago, IL, USA.

(c) Society of General Internal Medicine 2011

\section{Erratum to: J Gen Intern Med}

DOI 10.1007/s11606-010-1624-2

In the original publication, the surname of the eighth author is misspelled. The correct spelling is Nareckas.

The online version of the original article can be found at http://dx.doi. org/10.1007/s11606-010-1624-2.

Published online February 25, 2011 